\title{
As novas territorialidades da informação e o não- lugar da notícia
}

\section{The new territorialities of information and the non- place of news}

João Guilherme da Costa Franco Silva D’Arcadia ${ }^{1}$

Juliano Maurício de Carvalho ${ }^{2}$

Resumo: Este artigo busca relacionar o novo campo de fruição dos conteúdos noticiosos, aqui definidos como "novas territorialidades da informação", com o crescente avanço das mídias sociais. Para tanto, apresenta os conceitos de territorialidade e não-lugar e os articula com os resultados da pesquisa de consumo de mídia Digital News Report, do Reuters Institute, em suas edições de 2019 e 2020. Partindo da hipótese de que esses ambientes se efetivam como um espaço fluido e disperso de veiculação de conteúdos noticiosos e não noticiosos, o artigo busca contribuir com uma reflexão a respeito dos impactos dos novos espaços de fruição da informação, que, dadas suas características peculiares, tendem a estimular a disseminação não apenas de relatos factuais apurados, mas também de conteúdos enganosos ou materializados de maneira não profissional.

Palavras-chave: jornalismo; mídias sociais; consumo de mídia; territorialidades.

Abstract: This article seeks to relate the new field of enjoyment of news content, here defined as "new territorialities of information", with the growing advance of social. To this end, it presents the concepts of territoriality and non-place interacts with the results of the Reuters Institute's Digital News Report consumer survey, released in June 2019 and June 2020. Based on the hypothesis that these environments become effective as a fluid and dispersed space for the dissemination of

1 Universidade Estadual Paulista Júlio de Mesquita Filho (UNESP). Bauru, SP, Brasil. https://orcid.org/0000-0003-2801-9611.E-mail: joao.darcadia@unesp.br.

2 Universidade Estadual Paulista Júlio de Mesquita Filho (UNESP). Bauru, SP, Brasil. https://orcid.org/0000-0001-8515-2457.E-mail: juliano.mauricio@unesp.br. 
522 AS NOVAS TERRITORIALIDADES DA INFORMAÇÃO E O NÃO-LUGAR DA NOTÍCIA

news and non-news content, the article seeks to contribute to a reflection about the impacts of the new spaces for the enjoyment of information, given their peculiar characteristics, they tend to stimulate the dissemination not only of factual reports but also of misleading or unprofessional materialized content.

Keywords: journalism; social media; media consumption; territorialities. 


\section{Introdução}

A popularização das mídias digitais e das redes sociais energizou o debate a respeito das novas possibilidades de divulgação de conteúdo. As plataformas estanques tradicionais - impresso, rádio e TV - passam por profundo processo de ressignificação derivado deste cenário. Até mesmo a internet não é a mesma de quando de seu avanço a partir do fim do século passado. A rede mundial de computadores deixou de se circunscrever a computadores e ao $w w w$, para ser subsumida a uma rede mais ampla que inclui dispositivos móveis e outros foros de consumo e debate, dos quais o browser corresponde a apenas uma parte. ${ }^{3}$

Para além das consequências evidentes no reposicionamento de mercado das corporações de mídia, a configuração ainda incerta desses novos ambientes tem provocado mudanças expressivas na relação dos usuários com os processos simbólicos advindos dessa transformação - o que vale para as relações de consumo, o acesso a bens culturais etc. Neste artigo, buscamos avaliar esse impacto sobre o debate público, refletindo sobre como seu catalisador profissional preferencial desde o século XIX - o jornalismo - tem dialogado com o que chamaremos de novas territorialidades da informação. Partindo da hipótese de que as mídias sociais deslocaram o protagonismo da informação factual antes imantado pela imprensa convencional, intentamos entender as consequências deste retrato lacunar para a desinformação e/ou a deslegitimação da apuração profissional dos fatos.

As contribuições aqui expostas têm como arcabouço teórico os conceitos de territorialidade (MEDEIROS, 2009; LITLLE, 2002) e não-lugar (AUGÉ, 1992), considerados basilares para o entendimento a respeito dos espaços fluidos ora ocupados pela dispersão informativa. Tais reflexões decorrem do contraste metódico entre os resultados de três relatórios mundiais recentes a respeito do consumo de mídia: Pesquisa Brasileira de Mídia (Brasil, 2017), Digital News Report (Reuters

3 Ficou conhecido o resultado de pesquisa da Quartz/Mozilla em 2017, segundo a qual 55\% dos brasileiros entrevistados consideravam que “o Facebook é a internet”. Disponível em https:// d20x8vtl2bnfa2.cloudfront.net/InternetHealthReport_v01.pdf. Acesso em: 31 jul. 2019. 
Institute, 2019 e 2020) e Anuário da Comunicação (OberCom, 2018). Para este artigo, elegemos de maneira sintética as conclusões dos estudos da Reuters, correlacionando-o a eventos cujo papel das mídias digitais parece ter sido decisivo neste período.

\section{As territorialidades da informação}

O conceito de territorialidade está intimamente ligado à apropriação simbólica que se faz do território. Aplicado originalmente nos estudos de geografia, antropologia e urbanismo, limitou-se predominantemente aos espaços físicos - a aldeia, o campo, a cidade - para só depois ser incorporado aos espaços não físicos - as trocas simbólicas, a virtualidade, o ambiente digital.

Seja na geografia (SPOSITO, 2009) ou na antropologia (LITTLE, 2002), o conceito de territorialidade, para efeito deste estudo, dialoga com a necessidade de concretizar um espaço físico ou virtual que projete a seu frequentador um sistema de utilidade. Como define Sposito, a territorialidade "designa a qualidade que o território ganha de acordo com sua utilização ou apreensão pelo ser humano” (SPOSITO, 2009, p. 11).

Risério (2013), ao propor uma análise sistêmica da construção do Brasil com base nos ideários projetados em suas cidades, entende que a territorialidade é edificada a partir dos finos mecanismos de interferência no espaço urbano - do país ameríndio à especulação imobiliária dos dias atuais, passando pela colonização portuguesa, a escravidão e os fluxos imigratórios. A territorialidade, aplicada a este contexto, se dá por meio das relações construídas em determinado território: autóctones, se se constituírem enquanto objeto genuíno das comunidades, mas também exóticas, se foram sedimentadas por povos dominantes ou pelo poder econômico.

Territorialidade, além da acepção genérica ou sentido lato, onde é vista como a simples "qualidade de ser território", é muitas vezes concebida em um sentido estrito como a dimensão simbólica do território. Ao falar-se em territorialidade estar-se-ia dando ênfase ao caráter simbólico, ainda 
que ele não seja o elemento dominante e muito menos esgote as características do território (COSTA, 2004, p. 74).

Nesse primeiro ponto de vista, a territorialidade está ligada ao espaço por meio do qual há fruição nas relações humanas, no qual as trocas simbólicas se estabelecem. Para tanto, precisa ser incorporada por seus habitantes a partir de demarcações de identidade - em um intercâmbio constante entre reconhecimento e distinção.

Ao identificar esse percurso como efeito da "supermodernidade", Augé (1992) detalha o que considera um não-lugar: espaço desprovido de uma identidade clara, genérico e transitório. Confortável, pela similaridade com outros ambientes análogos.

Se um lugar pode se definir como identitário, relacional e histórico, um espaço que não pode se definir nem como identitário, nem como relacional, nem como histórico definirá um não-lugar. A hipótese aqui defendida é a de que a supermodernidade é produtora de não-lugares, isto é, de espaços que não são em si lugares antropológicos e que, contrariamente à modernidade baudelairiana, não integram os lugares antigos (AUGÉ, 1992, p. 61).

Àquela altura, os melhores exemplos de não-lugares eram os empreendimentos que se multiplicavam no mundo ocidental: aeroportos, rodovias expressas, freeshops, cadeias de hotel e parques temáticos. Iguais em toda parte, promovem o desapercebimento da relação espaço-tempo - de modo que é possível passar tempos em suas instalações, sem se dar conta de quantas horas de fato se passaram, bem como das alterações climáticas que ocorreram no período.

Ainda de maneira embrionária, Augé antecipava que o avanço das tecnologias de comunicação poderia estabelecer não-lugares, no que chamava de "redes a cabo ou sem fio, que mobilizam o espaço extraterrestre para uma comunicação tão estranha que muitas vezes só põe o indivíduo em contato com uma outra imagem de si mesmo" (1992, p. 74). Em 2019, em entrevista ao jornal El País, o autor revisitou seu 
conceito ao asseverar que a internet havia colocado a humanidade em estado de não-lugar permanente.

Antes de verificar essas implicações no ambiente comunicacional contemporâneo, objeto desta reflexão, cabem outras contribuições a respeito da desterritorialização provocada pelos fenômenos globalizantes.

Reconhecendo o termo como "cada vez mais incômodo", Canclini (2006) observa que um dos sinais da pós-modernidade é a transterritorialidade. Enquanto nas sociedades modernas as identidades eram territoriais e monolinguísticas, nos períodos subsequentes o que se viu foi a erupção de comunidades transterritoriais e multilinguísticas.

O fenômeno pode ser observado, para o autor, na busca por "itinerários desurbanizados" que contrariam a fruição citadina de um passeio turístico, por exemplo. Parques de diversão franquiados, como a Disney, tomam o lugar de roteiros históricos marcados pela fruição, unicidade e autenticidade.

A disseminação das novas tecnologias, em outra frente, deslocaria as manifestações da cidadania de seus espaços clássicos de participação política para as abordagens frutificadas pelos meios de comunicação.

Estes meios eletrônicos que fizeram irromper as massas populares na esfera pública foram deslocando o desempenho da cidadania em direção às práticas de consumo. Foram estabelecidas outras maneiras de se informar, de entender as comunidades a que se pertence, de conceber e exercer os direitos (CANCLINI, 2006, p. 39).

A desterritorialização passa a ser uma percepção cultural. Bens de consumo deixam de ter um lugar de origem evidenciado - a cadeia de produção, muitas vezes, inclui dezenas de países até que receba uma etiqueta de grife. Multinacionais e marcas transnacionais espalham seus produtos em todas as nações ocidentais, distribuídos em cadeias de supermercados igualmente estandardizadas: não coisas, vendidas em não-lugares.

Ortiz (2000) se detém no conceito de reterritorialização no contexto da mundialização da cultura e dos bens de consumo simbólicos. $\mathrm{O}$ 
autor salienta que o redesenho das territorialidades é uma premissa ontológica dos mass media.

Os meios de comunicação contêm uma dimensão que transcende suas territorialidades. O circuito técnico sobre o qual se apoiam as mensagens é também responsável por um tipo de civilização que se mundializa. Filmes, anúncios publicitários, música popular e séries televisivas são formas de expressão que circulam no seu interior, independentemente de suas origens (ORTIZ, 2000, p. 60).

Belochio (2009) nos lembra que o jornalismo também possuía um território institucionalizado, cuja relativa estabilidade foi abalada pelo surgimento e disseminação das novas tecnologias, em um processo de desterritorialização. Passado o período de ruptura, as estruturas se reorganizam em um processo de reterritorialização, "compreendida como a reorganização de um sistema, que mescla características de sua identidade tradicional com distintos parâmetros de funcionamento" (BELOCHIO, 2009, p. 205).

\section{O mapa do consumo de notícias}

A fim de delinear o que chamamos aqui de novas territorialidades da informação, emprestamos os dados fornecidos pelas edições de 2019 e 2020 dos relatórios Reuters Digital News Report, que analisam o consumo dos produtos midiáticos, por plataforma, em 38 países das Américas, Europa e Ásia. Trata-se da oitava edição do estudo, considerado importante por apresentar aspectos quantitativos e qualitativos. Para efeito deste artigo, utilizamos os dados verificados no Brasil. ${ }^{4}$

Na série histórica observada desde 2013, a configuração das fontes de notícias consultadas pela maioria dos brasileiros já demonstra uma

4 Foram ouvidas 2.013 pessoas no país. Em todo o estudo, mais de 73 mil entrevistas foram realizadas. 
tendência à cristalização de novos espaços para consumo de informações factuais, capitaneada sobretudo pelas mídias sociais.

Gráfico 1 - Fontes de notícias no Brasil, por plataforma

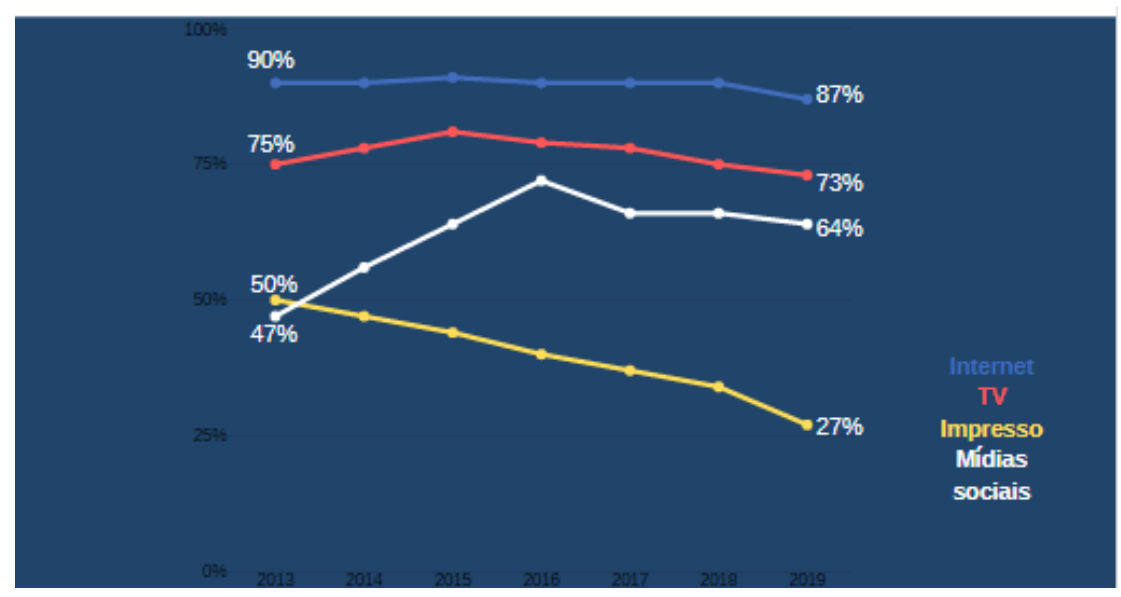

Fonte: os autores

Como se observa, no intervalo de sete anos, a internet (incluindo mídias sociais) se manteve no topo entre as plataformas mais acessadas com o objetivo de se obterem notícias. A TV, que ainda ocupa papel de destaque no Brasil, foi pela primeira vez superada pelas mídias sociais, ainda que praticamente empatadas. A mídia impressa vem sofrendo quedas sucessivas e hoje é acompanhada por $23 \%$ da população entrevistada. O rádio não consta neste levantamento, ${ }^{5}$ mas $51 \%$ dos entrevistados ouvidos na pesquisa de 2019 afirmam ter ouvido algum podcast no mês anterior ao estudo, o que vem sendo entendido como uma manifestação de ressignificação da cultura audiofônica. ${ }^{6}$

5 Pesquisa realizada pelo Ibope em 2019 em treze regiões metropolitanas indica que 89\% dos entrevistados dizem ouvir rádio diariamente. Disponível em: http://www.acaert.com.br/ ibope-media-divulga-infografico-que-detalha-o-consumo-de-radio-no-brasil\#.XVmmJuNKjIU. Acesso em: 13 ago. 2019.

6 Em agosto de 2019, as Organizações Globo, maior grupo de mídia do Brasil, anunciaram a criação de dezesseis podcasts disponibilizados em seu portal de notícias Gl e em plataformas de acesso sob demanda. 
A ascensão das mídias sociais para consumo de notícias chama a atenção porque, neste quesito, não estão incluídos os entrevistados que acessam a internet por meio de navegadores $(w w w)$, e sim aqueles que se valem da rede exclusivamente para acessar suas páginas pessoais. $\mathrm{O}$ relatório da Reuters dedica uma seção específica para apresentar o crescimento exponencial dos aplicativos de mensagens para obtenção de notícias - com destaque para o WhatsApp no Brasil (48\% dos entrevistados, 5\% a menos que no levantamento de 2019). De acordo com o documento, os brasileiros continuam sendo usuários assíduos das mídias sociais. No quesito mídias sociais e aplicativos de mensagens, o WhatsApp só fica atrás seis pontos percentuais do Facebook na preferência dos internautas brasileiros.

Os relatórios de 2019 e 2020 sinalizam para o grande impacto desses serviços em processos decisórios, como nas eleições presidenciais de 2018. Meses antes, durante greve de caminhoneiros que paralisou a maior parte das redes de transporte no país, o app se tornou um ambiente paralelo de troca de informações, difundindo relatos enganosos e provocando pânico entre aqueles que acreditavam que os suprimentos estavam acabando.

A premência do compartilhamento de conteúdos enganosos ganhou nova onda de preocupação com a pandemia de coronavírus registrada no primeiro semestre de 2020. Pesquisa conduzida pela Escola Nacional de Saúde Pública (ENSP/Fiocruz/2020) indica que a maior parte das representações falsas que circularam a respeito da doença foi compartilhada pelo WhatsApp - o que dificulta a identificação de sua origem, dado o caráter privativo do aplicativo de mensagens.

No compasso em como a adesão aos novos ambientes cresceu, a confiança em "notícias em geral" (news overall) caiu $11 \%$ entre os levantamentos de 2018 e 2019, e subiu 3\% entre 2019 e 2020, atingindo a marca de $51 \%$. A descrença na mídia tradicional foi estimulada no pleito eleitoral, drenando apoios das duas candidaturas mais expressivas para os ambientes informativos que aqui chamaremos de perijornalísticos. Adota-se o prefixo peri-, que significa em volta de, porque, embora 
os aplicativos de mensagens sabidamente não tenham como finalidade primeira a divulgação de informações noticiosas, seu uso informativo acaba orbitando as demais funcionalidades.

\section{0 não-lugar da notícia}

Reconhecidas pela flexibilidade e dinâmica entre seus participantes (MARTINO, 2015), as mídias sociais e os aplicativos de mensagens assumiram importante protagonismo na disseminação de conteúdos, conforme demonstrado até aqui. Sua imprevisibilidade de alcance e a possibilidade de anonimato engendram o que consideramos ser o não-lugar da notícia nos dias atuais.

Diferentemente do que preconizam manuais deontológicos (BERTRAND, 1999; FENAJ, 2007), a informação que circula nesses ambientes muitas vezes não resiste a um protocolo básico de aferição a respeito de sua confiabilidade: os conteúdos não são assinados, e, portanto, não há autores que se responsabilizem pelo material exposto. A data das publicações não pode ser verificada, e o tripé básico de apuração (entrevista, coleta de dados e investigação) nem sempre se efetiva. Mais graves são a indistinção entre os gêneros (informativo, opinativo e interpretativo) e a indefinição a respeito dos conteúdos jornalísticos e publieditoriais - que, embora presentes nas plataformas tradicionais, são menos perceptíveis nas redes digitais.

Essa confluência de fatores leva à disseminação do que se convencionou chamar de fake news - ou notícias falsas, em livre tradução, o que para Träsel (2018) representa um oximoro: figura de linguagem em que palavras antagônicas aparecem justapostas, de modo a se excluírem mutuamente. Novamente, a disseminação de relatos enganosos não é prerrogativa dos novos ambientes, mas neles encontrou a capilaridade necessária para se manifestar com maior liberdade e menos sanções. ${ }^{7}$

7 Em 2017, o Tribunal Superior Eleitoral (TSE) chegou a criar conselho consultivo para avaliar os impactos das notícias falsas e evitar sua disseminação. O grupo de trabalho não apresentou resultados práticos até as eleições de 2018. 
Embora não haja dados disponíveis para essa constatação, é possível antever que muitos usuários das novas tecnologias de circulação de conteúdos já não eram consumidores contumazes de notícias produzidas pela imprensa convencional.

Segundo o Indicador de Alfabetismo Funcional (Inaf/2018), apenas 12\% da População Economicamente Ativa no país tem condições de compreender e elaborar textos de diferentes tipos, como uma mensagem ou uma argumentação - editoriais e textos de jornal, de acordo com exemplo mencionado pelo próprio estudo.

As habilidades de compreensão de códigos, que tornam o indivíduo proficiente em sua língua, são consideradas indispensáveis para a fruição de textos minimamente complexos, como são os conteúdos noticiosos.

No entanto, essas mesmas habilidades não são requeridas para a compreensão básica de produções verbais e não verbais expostas de maneira fragmentária nas mídias sociais e nos aplicativos de mensagens. O não-lugar providenciado por esses ambientes, pode-se dizer, foi preenchido por uma espécie de conteúdo que não encontrava guarida na produção jornalística tradicional: materiais truncados, rudimentares, mentirosos, enganosos, atemporais, entre outras características.

Naturalmente, não se deve debitar essa capilaridade tão somente ao problema do analfabetismo funcional do país, uma vez que o fenômeno de adesão aos conteúdos falsos é observado no mundo todo, inclusive entre os países desenvolvidos.

Pode-se atribuir essa adesão universal aos materiais perijornalísticos também à arquitetura noticiosa (CANAVILHAS, 2014) de parte dos relatos enganosos - bastante semelhante à construção do texto noticioso (títulos, lides, fotos e até entrevistas, por exemplo) -, à afinidade que o postulado mentiroso estabelece com as ideias preconcebidas do interlocutor - ou viés de confirmação (VALLONE et al., 1985) - e até a certo desprestígio que a busca pela identificação objetiva dos fatos vivencia no mundo contemporâneo, no que ficou consagrado como pós-verdade (D’ANCONA, 2018). Essa conjunção de fatores é fortalecida pela ubiquidade das tecnologias digitais de comunicação. 
O viés de confirmação exprime perspectivas de vida já sedimentadas pela história de vida e pelo contexto social do interlocutor, de modo que as postulações externas que lhe são apresentadas ganham maior permeabilidade quando estão sintonizadas com essas crenças, e encontram maior resistência nas situações em que há discordâncias com esse ponto de vista prévio - mesmo quando a confrontação se mostra irrefutável. Em vez de interpretar os signos cotidianos como uma possibilidade de engrandecimento pessoal e intelectual ou até mesmo como um convite à mudança de paradigma, o interlocutor crê que utiliza os estímulos externos apenas para chancelar suas visões de mundo ou para conspirar contra aqueles que manifestam algo que não fala a suas convicções pessoais e inatas. O raciocínio tautológico pode ser encarado como um sintoma dessa perspectiva.

Definida de maneira sintética como um "discurso inútil” por Abbagnano (2002) em seu Dicionário de Filosofia, a tautologia se manifesta em raciocínios redundantes e ilógicos, por deturbar as relações de causa e consequência ou simplesmente propor uma economia intelectual ao abrir mão da reflexão sistemática. No exemplo do autor, temos a frase: "quinze minutos antes de morrer, ainda estava vivo" - ou seja, uma obviedade desnecessária, a menos que tenha valor estético no contexto da literatura.

Em Barthes (2001, p. 172), a tautologia é "um procedimento verbal que consiste em definir o mesmo pelo mesmo". Trata-se de um refúgio, para quem não encontra explicações suficientes para dar conta da complexidade dos eventos a sua volta. "Ora, toda a recusa da linguagem é uma morte. A tautologia fundamenta um mundo morto, um mundo imóvel" (2001, p. 173). A proposição tautológica é um dos componentes do mito barthesiano, uma "fala roubada" que provoca economia de significados ao apresentar um novo signo, erigido a partir de várias outras características (como omissão da história, a quantificação das qualidades, entre outras). Relacionamos o viés de confirmação à tautologia porque ambos buscam espaços de conforto diante da natureza poliédrica dos acontecimentos, uma espécie de atalho intelectual que não nega 
as mentiras nem admite as verdades, porque simplesmente se abstém de elaborar este tipo de julgamento.

\section{A caminho da reterritorialização?}

O que este artigo buscou defender é que as principais características das mídias sociais - compreendidas pela flexibilidade e pelo dinamismo entre seus usuários - provocam uma nova relação de consumo de informação que não está mais ligada aos seus espaços convencionais de materialização - jornais, revistas, rádio, TV e a própria web. Nessas territorialidades, os códigos de uso e conduta ainda não estão bem definidos, nem as políticas públicas de regulamentação, que não são objeto deste estudo.

Diante da crescente predileção pelas mídias sociais para se obter informação - noticiosa ou não - observam-se tentativas cada vez mais frequentes da mídia convencional em se reposicionar nestes espaços, como a criação de listas de newsletter pelo WhatsApp, a elaboração de reportagens em novos formatos (interativos, imersivos, colaborativos e transmidiáticos) e a manutenção de agências de checagem de fatos. Ainda assim, os esforços chegam depois de estabelecido o não-lugar da notícia, permeado por muita desinformação perijornalística - conteúdos enganosos que orbitam a arquitetura noticiosa - e cacofonia.

O reposicionamento definitivo é urgente, menos por questões ligadas à reserva de mercado, e mais pela necessidade civilizacional de oferecer ao debate público relatos condizentes com a representação equilibrada dos fatos.

\section{Referências}

ABBAGNANO, Nicola. Dicionário de filosofia. São Paulo: Martins Fontes, 1998. AGÊNCIA FIOCRUZ DE NOTÍCIAS (2020). Pesquisa revela dados sobre "fake news" relacionadas à Covid-19. Disponível em: https://agencia.fiocruz.br/pesquisa-revela-dados-sobre-fake-news-relacionadas-covid-19. Acesso em: 18 maio 2020.

AUGÉ, Marc. Não Lugares: introdução a uma antropologia da supermodernidade. Campinas: Papirus, 1994. 
BARTHES, Roland. Mitologias. Rio de Janeiro: Bertrand Brasil, 2001. BELOCHIO, Vivian. Jornalismo digital e colaboração: sinais da desterritorialização. Estudos em Jornalismo e Mídia, ano VI, n. 2, p. 203-216. Florianópolis, UFSC, jul.-dez. 2009.

BERTRAND, Claude-Jean. A deontologia das mídias. Bauru: Edusc, 1999.

BRASIL. Presidência da República, Secretaria de Comunicação Social. Pesquisa brasileira de mídia 2016: hábitos de consumo de mídia pela população brasileira. Brasília: Secom, 2016.

CANAVILHAS, João (Org.). Webjornalismo: 7 caraterísticas que marcam a diferença. Covilhã: Livros Labcom, 2014.

CANCLINI, Néstor García. Consumidores e cidadãos: conflitos multiculturais da globalização. Rio de Janeiro: Editora URFJ, 2006.

CARDOSO, G.; BALDI, V. et al. Relatórios-Obercom-Fake-News. 2018.

COSTA, Rogério Haesbaert. O mito da desterritorialização: do "fim dos territórios" à multiterritorialidade. Rio de Janeiro: Bertrand Brasil, 2004.

D’ANCONA, Matthew. Pós-verdade: a nova guerra contra os fatos em tempos de fake news. Barueri: Faro, 2018.

FEDERAÇÃO NACIONAL DOS JORNALISTAS - Fenaj. Código de Ética dos Jornalistas Brasileiros. 2007. Disponível em: http://www.fenaj.org.br/federacao/cometica/ codigo_de_etica_dos_jornalistas_brasileiros.pdf. Acesso em: 17 ago. 2019.

INSTITUTO PAULO MONTENEGRO. INAF Brasil 2018: resultados preliminares. São Paulo, 2018.

LITTLE, P. E. Territórios sociais e povos tradicionais no Brasil: por uma antropologia da territorialidade. Série Antropologia, n. 322, Brasília, 2002.

MARTINO, L. Teoria das mídias digitais. Petrópolis: Vozes, 2015.

MEDEIROS, R. M. V. Território, espaço de identidade. In: SAQUET, M. A.; SPOSITO, E. S. Territórios e territorialidades: teorias, processos e conflitos. São Paulo: Expressão Popular, 2009, cap. 10, p. 217-227.

ORTIZ, Renato. Mundialização e cultura. São Paulo: Brasiliense, 2000.

REUTERS INSTITUTE. Digital News Report 2020. Disponível em: https://bit. ly/2C7uv4m. Acesso em: 15 jul. 2020.

REUTERS INSTITUTE. Digital News Report 2019. Disponível em: https://bit. ly/3eA2vDo. Acesso em: 15 jul. 2020.

RISÉRIO, Antonio. A cidade no Brasil. São Paulo: Editora 34, 2013.

TRÄSEL, M.; LISBOA, S.; REIS, G. Indicadores de credibilidade no jornalismo: uma análise dos produtores de conteúdo político brasileiros. 27 ENCONTRO ANUAL DA COMPÓS, 2018, Belo Horizonte, Brasil.

VALONNE, R.; LEE, R.; MARK, R. L. The Hostile Media Phenomenon: Biased Perception and Perceptions of Media Bias in Coverage of the Beirut Massacre. Journal of Personality and Social Psychology. v. 49, n. 3,p. 577-585, set. 1985.

WARDLE, Claire. Information Disorder: Toward an Interdisciplinary Framework for Research and Policy Making. Strasbourg: Council of Europe, 2017. 


\section{Sobre os autores}

João Guilherme da Costa Franco Silva D’Arcadia - Doutorando no Programa de Pós-graduação em Mídia e Tecnologia da Faculdade de Arquitetura, Artes e Comunicação (FAAC) da Universidade Estadual Paulista Júlio de Mesquita Filho (Unesp). Mestre em Comunicação (Unesp) e Graduado em Comunicação Social/Jornalismo (Unesp). No presente artigo, os dois pesquisadores atuaram em conjunto na definição do que consideram "novas territorialidades da informação e o não-lugar da notícia”, expostas na reflexão. João D’Arcadia conduziu a elaboração do texto, com o suporte de Juliano Maurício de Carvalho na interpretação dos achados de pesquisa e encaminhamentos ligados à análise dos dados e à redação final.

Juliano Maurício de Carvalho - Livre-docente em Políticas de Comunicação, Mídia e Indústrias Criativas. Pós-doutorado pela Universidade de Sevilha (2011) e Universidade Carlos III de Madri (2009). É Vice-coordenador do Curso de Doutorado do Programa de Pós-Graduação em Mídia e Tecnologia, docente do Programa de Pós-Graduação Comunicação Midiática da Faculdade de Arquitetura, Artes e Comunicação (FAAC) da Universidade Estadual Paulista Júlio de Mesquita Filho (Unesp). Doutor em Comunicação Social pela Universidade Metodista de São Paulo (Umesp), mestre em Ciência Política pela Universidade Estadual de Campinas (Unicamp) e bacharel em Jornalismo pela Pontifícia Universidade Católica de Campinas (PUC-Campinas). No presente artigo, os dois pesquisadores atuaram em conjunto na definição do que consideram "novas territorialidades da informação e o não-lugar da notícia", expostas na reflexão. João D’Arcadia conduziu a elaboração do texto, com o suporte de Juliano Maurício de Carvalho na interpretação dos achados de pesquisa e encaminhamentos ligados à análise dos dados e à redação final.

Data de submissão: 18/02/2020

Data de aceite: 07/08/2020 